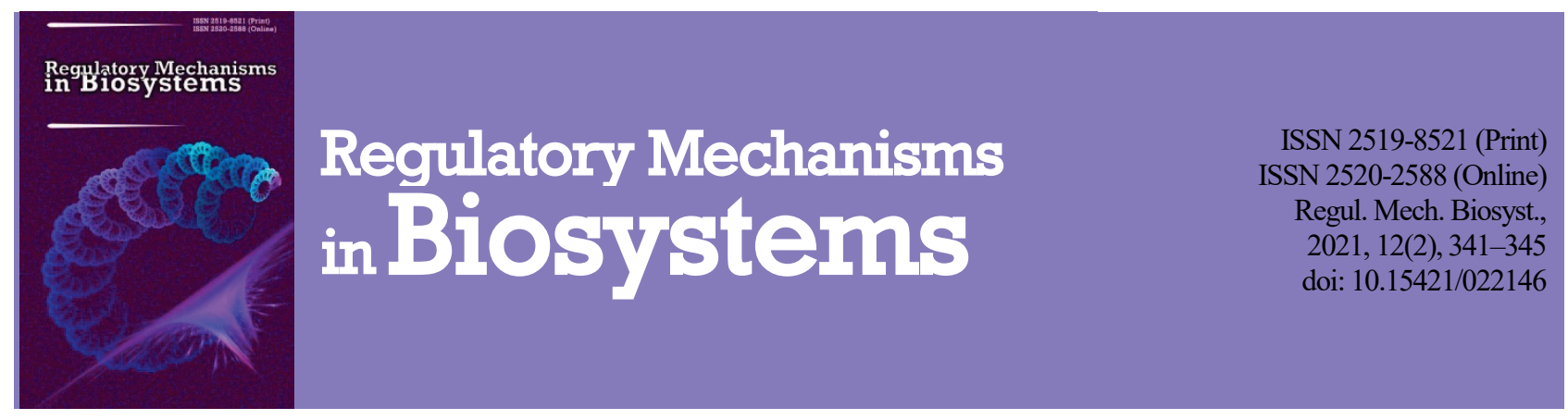

\title{
Pathohistological changes in the intestine, lungs and liver of sheep with spontaneous strongyloidiasis
}

\author{
S. Sorokova*, V. Yevstafieva*, O. Shchebentovska**, O. Barabolia*, K. Suprunenko* \\ * Poltava State Agrarian Academy, Poltava, Ukraine \\ **Stepan Gzhytskyi National University of Veterinary Medicine and Biotechnologies, Lviv, Ukraine
}

Article info

Received 02.05.2021

Received in revised form 01.06 .2021

Accepted 03.06.2021

Poltava State Agrarian Academy, Skovorodyst., 1/3,

Poltava, 36003, Ukraine.

Tel.: +38-066-089-25-61

E-mail:evstva@ukr.net

Stepan Gzhytskyi National

University of Veterinary

Medicine and Biotechnologies

Pekarska st., 50,

Lviv, 79010, Ukraine.

Tel.: +38-050-312-57-36

E-mail:

schebentovskaolga@gmail.com

\begin{abstract}
Sorokova, S., Yevstafieva, V., Shchebentovska, O., Barabolia, O., \& Suprunenko, K. (2021). Pathohistological changes in the intestine, lungs and liver of sheep with spontaneous strongyloidiasis. Regulatory Mechanisms in Biosystems, 12(2), 341-345. doi:10.15421/022146

Sheep diseases of invasive and non-invasive etiology are among the restrictive factors for Ukrainian sheep-breeding. The helminthiases are among the most widespread parasitical diseases, and particularly strongyloidiasis causes significant losses for sheep farms in cases of severe course. Young sheep are the most susceptible, showing growth and developmental lag, and death occurs in cases of high invasiveness due to severe pathologies induced by the parasites. Thus the aim of the present work was to study the morphological and histological changes in the intestine, lungs and liver of sheep with strongyloidiasis. Results of pathoanatomy showed that under spontaneous sheep strongyloidiasis with the intensity of the invasion from 50 to 136 specimens of nematodes, the main pathological changes occur at Strongyloides localization sites: intestine and parenchymatous organs (lungs and liver). Particularly, the small intestine showed catarrhal desquamative enteritis. Morphological changes of its mucosa demonstrated necrosis of the apical part of the villi, desquamation of epithelium, constriction and decrease of intestinal crypts. At the same time, massive diffusive cell infiltrates were detected in the intestinal mucosa lamina propria with the prevalence of eosinophilic leukocytes, inflammatory thickening of villi cylindrical epithelium and its mucous metamorphosis, pyknosis and lysis of enterocyte nuclei. In the large intestine, necrosis of the mucosa was detected, with edema, effusion of serum-cell exudate in its canal, diffusive infiltration of lymphocytes, eosinophils and plasma cells in the intestinal mucosa lamina propria. Lung tissue demonstrated parasite larvae localized in canals of the bronchi and in alveoli. These sites had diffusive hemorrhages in lung parenchyma, signs of inflammation and thickening of interstitial tissue caused by damage to vessel walls due to migration of parasite larvae. Histological changes in the liver of sheep with strongyloidiasis showed the development of granular dystrophy and necrotic changes in hepatocytes.
\end{abstract}

Keywords: Strongyloides papillosus; invasion; post-mortem diagnosis; internal organs; pathomorphological survey.

\section{Introduction}

For modern farming, restoration and development of sheep-breeding may be promising in terms of increasing effective land use, population employment rate and supply of the national sector of meat processing and light industry with raw material with curative properties (Banerjee et al., 2009; Anteneh \& Yadav, 2017). One of factors that decreases the efficacy of sheep-breeding development and causes economic losses is helminthiases, particularly strongyloidiasis caused by Strongyloides papillosus (Dimitrijevic et al., 2016; Boyko \& Brygadyrenko, 2017, 2019a, 2019b; Boyko et al., 2009, 2020). Scientists state that sheep strongyloidiasis is the most widespread endemic helminthiasis in the world (Bonfoh et al., 1995; Abebe et al., 2010; Balicka-Ramisz et al., 2013; Asmare et al., 2016). S. papillosus parasitism has been registered in sheep in Tunis, Egypt, Poland, Ethiopia, Nigeria, Gambia, Togo, Sudan, Brazil, Italy (Giannetto, 2006; Nwosu et al., 2007; Eisa et al., 2017; Dugassa et al., 2018).

Invasion leads to lag in growth and development in young sheep, development of diarrhea, anemia, ataxia and death (at high intensity of invasion) (Nakanishi et al., 1993; Manfredi, 2006; Kobayashi et al., 2009). Based on literature data, under conditions of severe experimental S. papillosus invasion of goats, approximately $6 \%$ of animals died due to anemia caused by liver damage. Scientists also stated that with experimental invasion by S. papillosus larvae, they were detected in the lungs, trachea and esophagus already in 90 hours, which indicates their fast migration via the bloodstream (Nwaorgu \& Connan, 1980). Other scientists found larvae in the myocardium and mammary glands along with hemorrhagic inflammation of intestinal mucosa during pathoanatomical dissection of sheep, experimentally infected by $S$. papillosus. At the same time, pathological changes were absent in other organs (Turner, 1959; Nwosu et al., 2007).

Studying the mechanism of instant death of calves by strongyloidiasis, scientists performed a set of pathomorphological researches to establish the impact of nematodes on infected organisms. Their data indicates no visible macroscopic changes in internal organs excepting minor inflammation signs in the lungs. Histology showed infiltration by cellular cardyomyocytes. Biochemical and hematological methods showed no crucial physiological deviations, which made it impossible to clarify pathological mechanisms of calf instant death by strongyloidiasis (Taira, 1992; Tsuji et al., 1992; Ura et al., 1992; Ura, 1993). Subcutaneous tissue edemas, catarrhal enteritis, dystrophic changes in the liver and kidneys, lung edema and interstitial pneumonia development were found in goats experimentally infected by $S$. papillosus. Besides that, allergic dermatitis developed at the skin sites of larvae application or injection of their metabolites. Pathognomonic symptoms of goat experimental strongyloidiasis were anemia and hypophosphatemia, mostly expressed in young animals (Pienaar et al., 1999). However, human S. stecoralis infection causes only insignificant intestinal damage developing asymptomatically during many years. Patients receiving prolonged corticosteroid therapy with undiagnosed strongyloidiasis often developed hyperinfection with high registered lethality (up to 87\%) (Ericsson et al., 2001; Beknazarova et al., 2016). Available literature provides enough information on the distribution, disease course, diagnosis and therapy of sheep strongyloidiasis. Some authors studied clinical manifestations and pathoanatomical changes in organs of animals under spontaneous and experimental infection. But there is a lack of detailed pathohistological studies of internal organs of 
sheep infected with spontaneous strongyloidiasis, which indicates the relevance of the selected topic. For this reason, our work was aimed at the study of morphological and histological changes in the intestine, lungs and liver of sheep with strongyloidiasis.

\section{Materials and methods}

The research was conducted during 2018-2020 at the Laboratory of Parasitology of Poltava State Agrarian Academy and the Educational and Research Laboratory of the Department of Normal and Pathological Morphology and Forensic Veterinary Medicine of Lviv National University of Veterinary Medicine and Biotechnologies named after S. Z. Gzycki. Pathological material was collected at slaughterhouses from East Friesian sheep, aged 6-8 months, infested with $S$. papillosus nematodes, which came from farms in the Poltava region. For pathohistological examination, pieces of the small, large intestine, liver, and lungs of sheep infested with S. papillosus were selected at an infestation intensity of 50 to 136 specimens of nematodes. In total, pathological material was selected from 27 infested sheep.

Organ fragments were fixed in a $10 \%$ aqueous solution of neutral formalin, washed and dehydrated in an ascending row of alcohols, followed by paraffin filling according to conventional methods. Slices $7 \mu \mathrm{m}$ thick were made from paraffin blocks on a MS-2 sled microtome. Dewaxed sections were stained with Mayer's hematoxylin and eosin (Romeis, 1954; Kiceli, 1962; Merkulov, 1969).

Pathohistological examinations, light microscopy and microphotography of the obtained histopreparations were performed using a Leica DM2500 microscope, a Leica DFC 450C camera and Leica Application Suite Version 4.4 software.
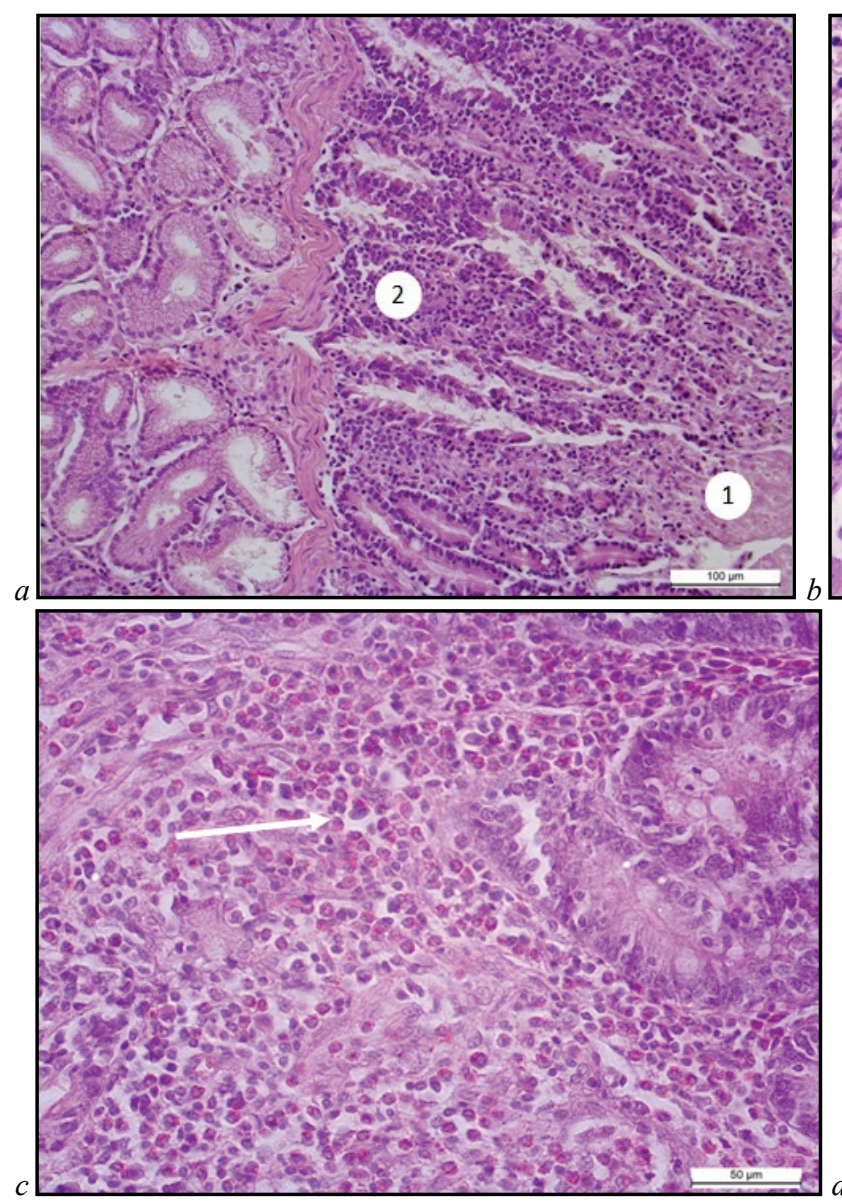

\section{Results}

Microscopic survey of the small intestine of sheep showed changes in the mucosa: diffusive thickening, edema, minor hyperemia, local spot-like hemorrhages. Duodenum content was viscous and dirty-yellow, with easily removable grey layers of admixtures. Histological study of the duodenum showed minor vessel reaction. Intestinal villi varied greatly and were deformed and flattened; crypts were shortened (Fig. 1a). The apical surface of the majority of villi was desquamated: enterocytes and goblet cells were peeled off in the intestinal canal. S. papillosus larvae were not detected among the epithelial cells at different stages of decay and mucous catarrh in the duodenum canal. Intensified mucous metamorphosis was characteristic. The number of enterocytes with acidophilic granules (Panetta cells) was notably decreased. Dystrophic changes were expressed also as cylindrical epithelium thickening to flattened forms with unclear contours, pyknosis and nuclei lysis, constriction of intestinal crypts. In mucosal lamina propria, edema and diffusive cell infiltration were detected (Fig. 1b, c). Duodenal crypts were distinct by depth. The muscle layer of duodenal mucosa was somewhat thickened and made of smooth muscles diverging at the sites of outlet ducts of Brunner's glands. Secretory cells of these glands were filled with mucin, their nuclei localized basally, the entire apical part filled with secretory granules. Mucus secretion intensified due to adaptive and compensative reaction (Fig. 1d).

Epithelium of the duodenum and jejunum was diffusively desquamated due to influence of S. papillosus. Villi were considerably shortened, edema and small hemorrhages were characteristic. The surface of the mucosa was covered by a significant amount of mucus and cellular detritus. Intensified desquamation of epithelium lead to the necrosis of apexes of the villi, and intensive polymorphocellular infiltration was detected in the sites of parasite localization (Fig. 2).
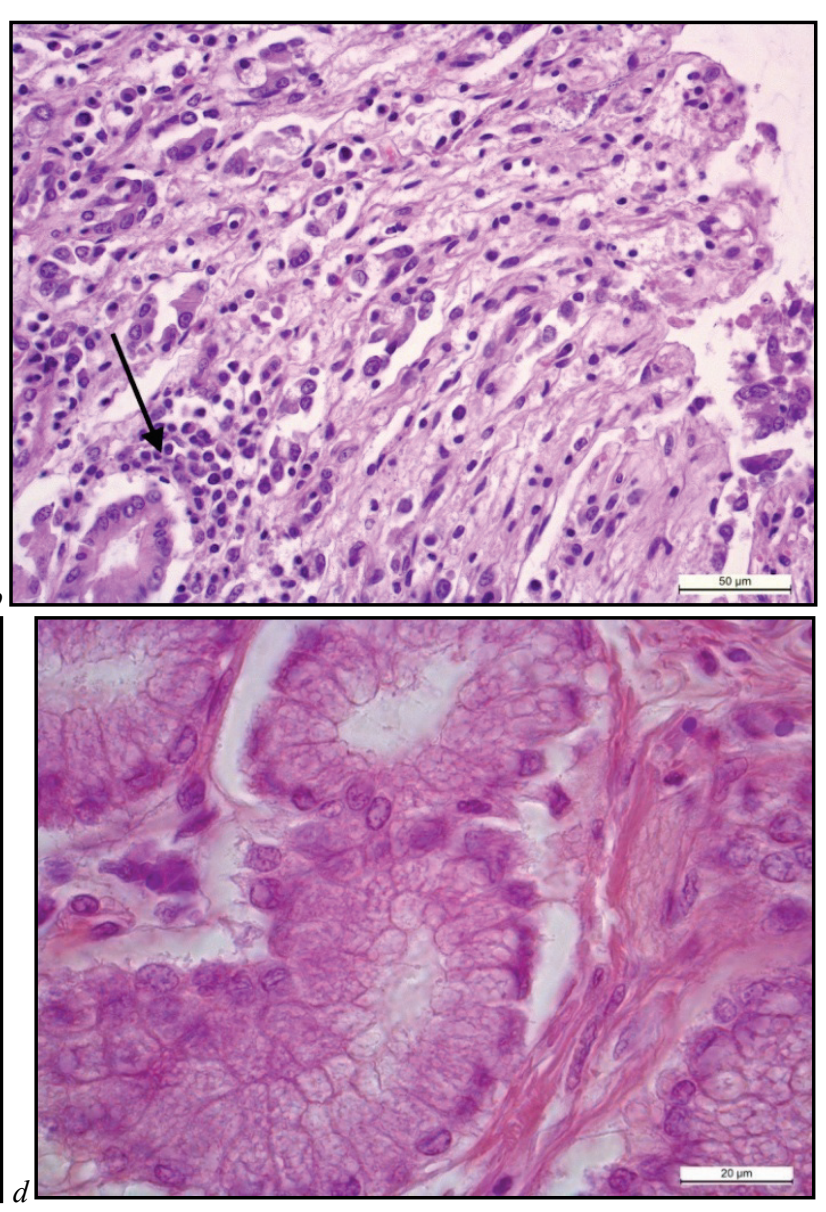

Fig. 1. Duodenum of sheep infected by S. papillosus: $a$ - desquamation of villi epithelium (1), expressed infiltration of mucosal lamina propria (2); $b$-cellular infiltration of mucosal lamina propria; $c$ - edema and cellular infiltration of crypts with prevalence of eosinophilic leukocytes; $d$-hypertrophy of Brunner's (duodenal) glands; haematoxylin and eosin 

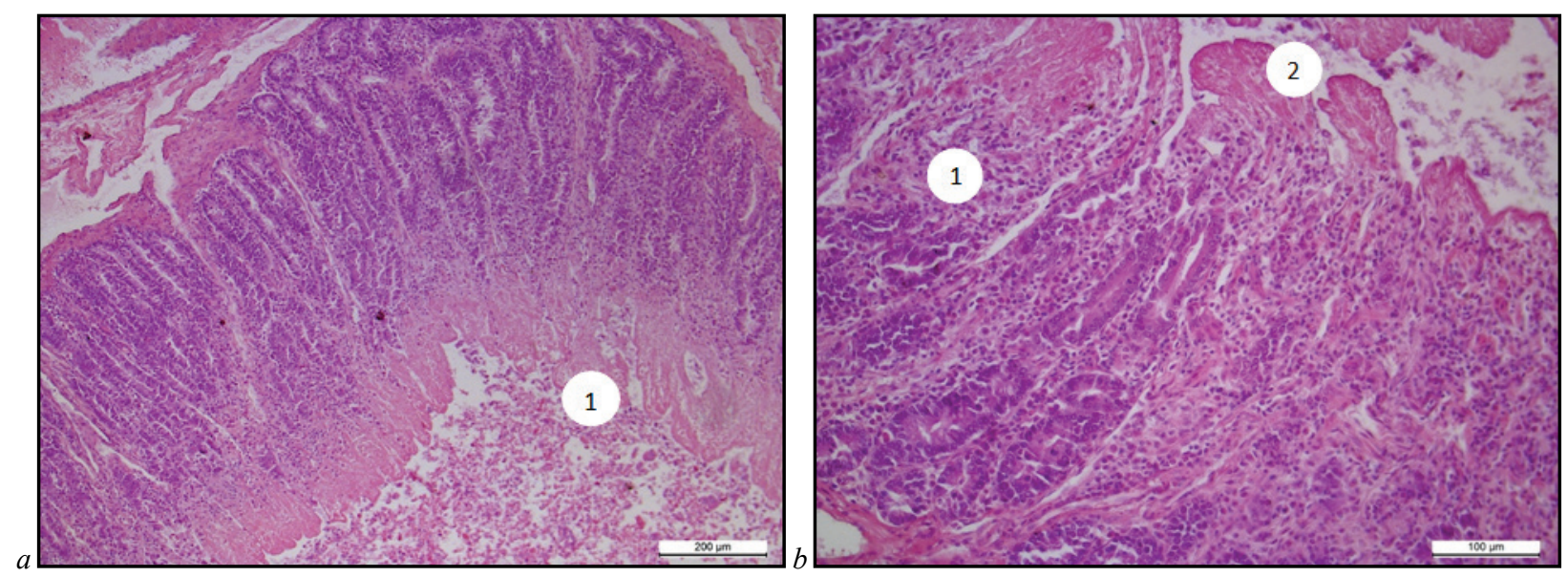

Fig. 2. Jejunum of sheep infected by S. papillusos: $a$-desquamation of mucous (1);

$b$ - edema of mucous lamina propria (1), necrosis of apex of villi (2); haematoxylin and eosin

Histologically the colon was shown to have: mucous necrosis, desquamation of mucocellular exudate in the intestinal canal (Fig. 3), diffusive infiltration of lymphocytes, eosinophils and plasma cells of mucosa lamina propria with its edema.

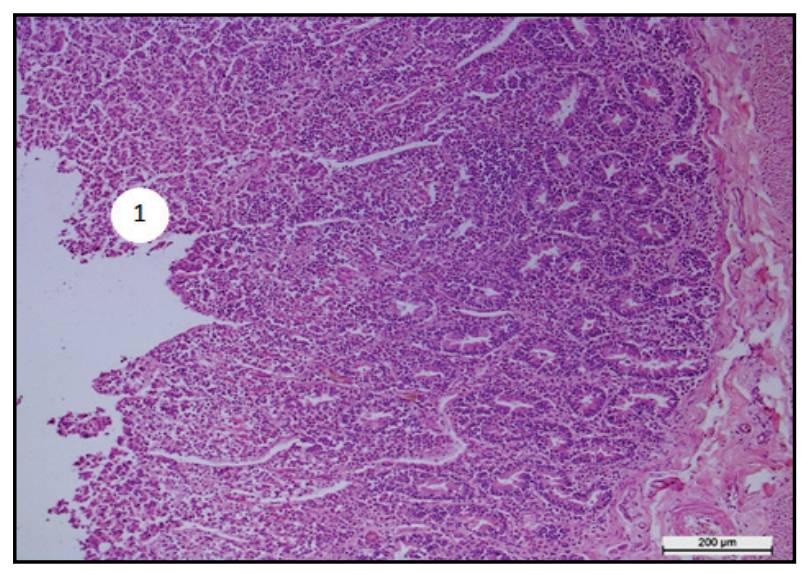

Fig. 3. Colon of sheep infected by S. papillosus: mucous necrosis (1); haematoxylin and eosin

Macroscopic survey of sheep lung indicated small hemorrhages in the pleura and the organ coloration from dark-red to scarlet; surface of cutting oozed with foamy liquid of reddish colour. Histology showed the intensive blood supply of lung vessels and capillaries, lymphocytes, histiocytes and macrophages infiltration in interstitial tissue, especially in perivascular and perobronchial (Fig. 4b). Small Strongiloides larvae were clearly visible in the canals of the alveoli and bronchi (Fig. 4a). Blood vessels were highly dilated with thinned walls and locally loosened; the canal was filled with plasma and erythrocytes, which caused edema in some damaged lung lobes. Alveolar canals had homogenic light-pink edema liquid with erythrocytes in places (Fig. 4c, d). Some of the alveolar epithelium was degenerated and desquamating (desquamative catarrh). It should be noted that inflammatory reaction with further interstitial tissue thickening were characteristic precisely on the tracks of larvae migration to the bronchi and in sites of their penetration into the alveolar canal. Macroscopic examination of the liver of sheep revealed a slight increase, the colour - from light brown to dark brown, from the surface of the incision anemic, dull. Histologically, the beam structure is preserved, hepatocytes are round, tightly adjacent to each other, intraparticle capillaries are compressed, around the central artery there is a cellular infiltration (Fig. 5).

Cytoplasm of the hepatocytes was unequally enlightened with welldeveloped granulation. Nuclei of the majority of hepatocytes were round with abundant chromatin with 1 or 2 nucleoli. However, there were hepatocytes with pyknotic or lysed nuclei. So, the main pathological changes of the spontaneous sheep strongyloidiasis were found in the intestine, lungs and liver, which indicates the development of inflammatory, dystrophic and necrobiotic processes in these organs.

\section{Discussion}

Analyzing scientific papers we can state that strongyloidiasis is the widespread invasion of different species of young animals; humans are also susceptible (Ericsson et al., 2001; Asmare et al., 2016). Most authors indicate an asymptomatic course of invasion, but there are data on instant calf death caused by strongyloidiasis (Ura et al., 1992; Ura, 1993). Thus establishing the pathological changes which develop in the sheep organism under S. papillosus invasion is a relevant and understudied question. We showed that with S. papillosus invasion at intensity of from 50 to 136 specimens of nematodes, pathological changes develop in the organisms of sick sheep not only in the parasites' locality, but in the liver and lungs as well. So, there were histologically detected catarrhal-desquamative inflammation and spot-like hemorrhages in the small and large intestines, dystrophic and necrotic signs in the mucosa. Interstitial pneumonia signs and lung edema were detected at the same time. Similar data were obtained from pathoanatomic study of a 10 week puppy affected by $S$. stercoralis. Particularly, the moderate edema was detected at the cutting around the anus, and the small intestine, especially duodenum, was swollen and had a significant amount of stinking yellowish mucous. The large intestine was moderately dilated and filled with a little amount of liquid, mucosa was thinned and hyperemic, with diffusive spot-like hemorrhages. A large number of small nematodes and larvae were detected microscopically among cellular infiltrate in the duodenum. The large intestine had dystrophic and necrotic changes, with necrosis of mucosa villi and hemorrhages. Moderate interstitial pneumonia developed in the lungs. The alveolar septa were thickened; peribronchial connective tissue had cellular infiltration of lymphocytes, histiocytes and macrophages, but without larvae. The moderate delymphatization was registered for the spleen and lymphatic nodes of the large intestine. Damage to other organs was not detected (Dillard et al., 2007).

Changes in the lungs of strongyloides-infected sheep developed due to larvae migration through the lung tissue, which was confirmed by their presence in histological slides. Fast migration of S. papillosus larvae through the bloodstream was evidenced by the presence of strongyloides larvae in the lungs, trachea and esophagus 90 hours after experimental infection of the sheep (Nwaorgu \& Connan, 1980). Also, we established the histological changes in the liver of sheep sick with strongyloidiasis. They were characterized by dystrophic changes, particularly granular dystrophy in hepatocytes and focal pyknosis of their nuclei. Changes in the liver of goats and sheep with experimental strongyloidiasis were also noted by some authors. Clinical manifestations in animals infected by S. papillosus included profuse diarrhea, dehydration, anorexia, cachexia, bruxism, foaming at the mouth, anemia and nervous symptoms such as ataxia, stupor and nystagmus. Pathoanatomical dissection revealed enteritis, encephalopathy, hepatosis causing liver rupture, nephrosis, lung edema, interstitial pneumonia. Approximately $6 \%$ of goats died due to liver rupture (Pienaar et al., 1999). Other works on sheep with experimental S. papillosus infection showed inflammation of intestine mucosa with absence of damage to other organs (Turner, 1959; Nwosu et al., 2007). 

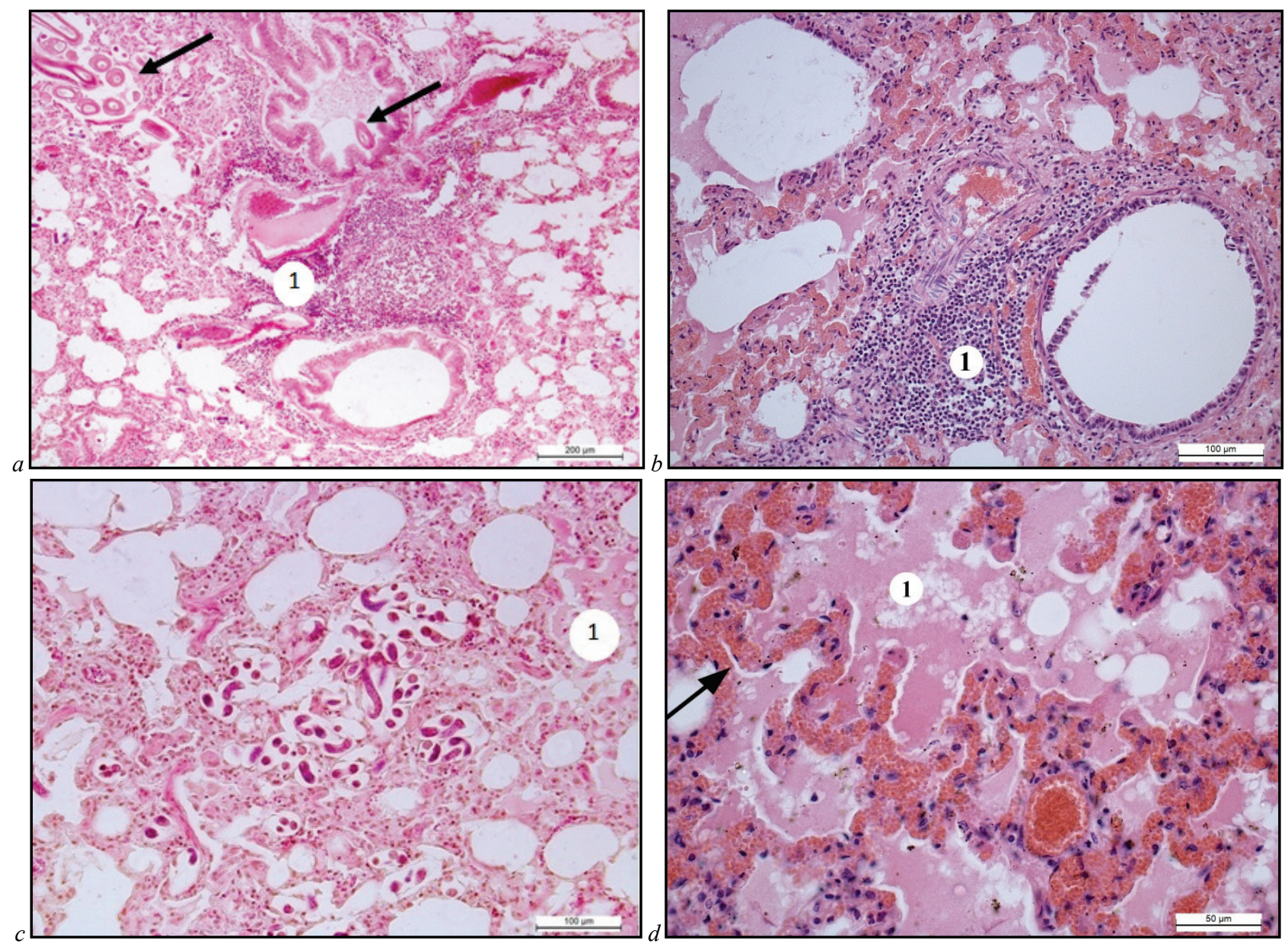

Fig. 4. Lungs of sheep infected by S. papillosus: a - Strongyloides larvae in canals of the bronchus and alveolus (arrow), desquamation of villi epithelium (l); $b$ - expressed perivascular and peribronchial cellular infiltration (1); $c$ - edema (1); $d$-interalveolar septums dilated and filled with enterocytes (arrow), accumulation of edema liquid in alveolus ( $I$ ); haematoxylin and eosin

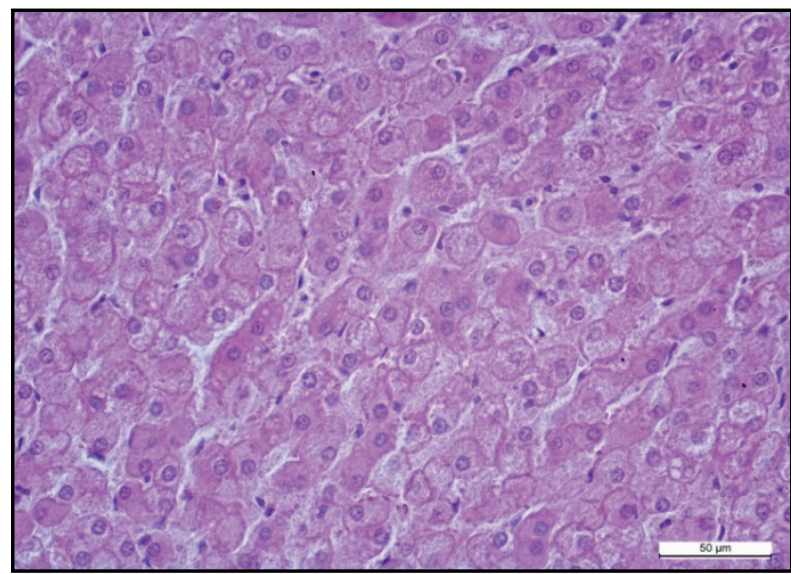

Fig. 5. Liver of sheep infected by S. papillosus:

granulated dystrophy of hepatocytes; haematoxylin and eosin

So, having analyzed the results of histological studies of particular organs from animals with spontaneous strongyloidiasis, we can state that the established morphological changes indicate mechanical, toxic and allergenic influence of the parasites, overall organism intoxication by nematodes' metabolites, connected to ontogenesis features of S. papillosus in the definitive host organism.

\section{Conclusion}

Histological examinations of individual organs of sheep infested with S. papillosus at the intensity of the invasion from 50 to 136 specimens found that the parasite causes morphological changes, not only in the place of their localization - in the small intestine, but also in the large intestine, where pathological changes are characterized by inflammatory, dystrophic, and necrotic processes of the mucous membrane. This leads to the appearance of indigestion in sick animals, "syndrome" of impaired absorption of nutrients from food, and, as a consequence, the development of anemia and cachexia. In addition, pathological changes in the lung tissue, characterized by edema, thickening of the alveolar walls, and infiltration of cellular elements of the bronchioles and blood vessels occur as a local reaction to the migration of the parasite through the lung tissue. At the same time, changes in the liver were observed, which were histologically characterized by the development of granular dystrophy and the appearance of necrobiotic phenomena in hepatocytes, which is a consequence of metabolic disorders and general intoxication of sheep by the products of Strongyloides. Our data on pathohistological changes in the body of sheep infected with $S$. papillosus indicate a negative impact of nematodes not only in their location, due to mechanical damage to the mucous membrane, but also to other organs and tissues such as the lungs and liver due to larval migration, allergies, and intoxication of animals. This should be taken into account during treatment, where in addition to anthelmintic therapy symptomatic treatment should be used.

\section{References}

Abebe, R., Gebreyohannes, M., Mekuria, S., Abunna, F., \& Regassa, A. (2010). Gastrointestinal nematode infections in small ruminants under the traditional husbandry system during the dry season in Southem Ethiopia. Tropical Animal Health and Production, 42(6), 1111-1117.

Anteneh, W., \& Yadav, K. R. (2017). A review sheep production system, yield, quality and preservation methods in Ethiopia. Greener Journal of Agricultural Sciences, 7(9), 243-254. 
Asmare, K., Sheferaw, D., Aragaw, K., Abera, M., Sibhat, B., Haile, A., Kiara, H., Szonyi, B., Skjerve, E., \& Wieland, B. (2016). Gastrointestinal nematode infection in small ruminants in Ethiopia: A systematic review and meta-analysis. Acta Tropica, 160, 68-77.

Balicka-Ramisz, A., Ramisz, G., \& Zychlińska-Buczek, J. (2013). The annual population dynamics of gastrointestinal nematodes in breeding sheep of the Silesian Foothills, Southern Poland. Annals of Parasitology, 59(4),163-167.

Banerjee, R., Mandal, P. K., Bose, S., Banerjee, M., \& Manna, B. (2009). Quality evaluation of meat, skin and wool from Garole sheep - a promising breed from India. Asian Journal of Animal Sciences, 3, 39 46.

Beknazarova, M., Whiley, H., \& Ross, K. (2016). Advocating for both environmental and clinical approaches to control human strongyloidiasis. Pathogens, 5(4), 59.

Bonfoh, B., Zinsstag, J., Ankers, P., Pangui, L. J., \& Pfister, K. (1995). Epidemiology of gastrointestinal nematodes in small ruminants in the plateau areas in Togo. Revue D'elevage et de Medecine Veterinaire des Pays Tropicaux, 48(4), 321-326.

Boyko, A. A., \& Brygadyrenko, V. V. (2017). Changes in the viability of Strongyloides ransomi larvae (Nematoda, Rhabditida) under the influence of synthetic flavourings. Regulatory Mechanisms in Biosystems, 8(1), 36-40.

Boyko, A., Brygadyrenko, V., Shendryk, L., \& Loza, I. (2009). Estimation of the role of antropo-zoonosis invasion agents in the counteraction to bioterrorism. In: Counteraction to chemical and biological terrorism in East European countries. NATO science for peace and security series A: Chemistry and biology. Springer Nature. Pp. 309-315.

Boyko, O. O., \& Brygadyrenko, V. V. (2019a). Nematocidial activity of aqueous solutions of plants of the families Cupressaceae, Rosaceae, Asteraceae, Fabaceae, Cannabaceae and Apiaceae. Biosystems Diversity, 27(3), 227-232.

Boyko, O. O., \& Brygadyrenko, V. V. (2019b). The impact of acids approved for use in foods on the vitality of Haemonchus contortus and Strongyloides papillosus (Nematoda) larvae. Helminthologia, 56(3), 202-210.

Boyko, O. O., Kabar, A. M., \& Brygadyrenko, V. V. (2020). Nematicidal activity of aqueous tinctures of medicinal plants against larvae of the nematodes Strongyloides papillosus and Haemonchus contortus. Biosystems Diversity, 28(1), 119-123.

Dillard, K. J., Saari, S. A., \& Anttila, M. (2007). Strongyloides stercoralis infection in a Finnish kennel. Acta Veterinaria Scandinavica, 49, 37.

Dimitrijevic, B., Jović, S., Ostojić-Andrić, D., Savić, M., Beckei, Ž., Davidović, V., \& Joksimović-Todorović, M. (2016). Infection with Strongyloides papillosus in sheep: Effect of parasitic infection and treatment with albendazole on basic haematological parameters. Biotechnology in Animal Husbandry, 32, 369-381.

Dugassa, J., Hussein, A., Kebede, A., \& Mohammed, C. (2018). Prevalence and associated risk factors of gastrointestinal nematodes of sheep and goats in Ziway Dugda District, Eastem Arsi Zone of Oromia regional state, Ethiopia. ARC Journal of Animal and Veterinary Sciences, 4(2), 6-18.

Eisa, N. Z., Babiker, S. A., \& Abdalla, H. S. (2017). Effect of natural gastrointestinal parasitic infection on fattening performance of Sudan desert sheep. Journal of Animal Sciences and Livestock Production, 1(1), 1-6.
Ericsson, C. D., Steffen, R., Siddiqui, A. A., \& Berk, S. L. (2001). Diagnosis of Strongyloides stercoralis infection. Clinical Infectious Diseases, 33(7), 1040-1047.

Giannetto, S. (2006). Biomorphology of gastrointestinal nematodes of small ruminants. Parassitologia, 48(3), 391-395.

Kiceli, D. (1962). Prakticheckaja mikpotehnika i gictohimija [Practical microtechniques and histochemistry]. Hungary Scientific Academy Publishing, Budapesht (in Russian).

Kobayashi, I., Kajisa, M., Farid, A. S., Yamanaka, A., \& Horii, Y. (2009). Paralytic ileus and subsequent death caused by enteric parasite, Strongyloides papillosus in Mongolian gerbils. Veterinary Parasitology, 162, 100-105.

Manfredi, M. T. (2006). Biology of gastrointestinal nematodes of ruminants. Parasitologia, 48(3), 397-401.

Merkulov, G. A. (1969). Kurs patologicheskoj tekhniki [Course of pathohistological techniques]. Medicine, Moscow (in Russsian).

Nakanishi, N., Nakamura, Y., Ura, S., Tsuji, N., Taira, N., Tanimura, N., \& Kubo, M. (1993). Sudden death of calves by experimental infection with Strongyloides papillosus. III. Hematological, biochemical and histological examinations. Veterinary Parasitology, 47, 67-76.

Nwaorgu, O. C., \& Connan, R. M. (1980). The importance of arrested larvae in the maintenance of patent infections of Strongyloides papillosus in rabbits and sheep. Veterinary Parasitology, 7(4), 339-346.

Nwosu, C. O., Madu, P. P., \& Richards, W. S. (2007). Prevalence and seasonal changes in the population of gastrointestinal nematodes of small ruminants in the semi-arid zone of North-Eastem Nigeria. Veterinary Parasitology, 144, 118-124.

Pienaar, J. G., Basson, P. A., du Plessis, J. L., Collins, H. M., Naude, T. W., Boyazoglu, P. A., Boomker, J., Reyers, F., \& Pienaar, W. L. (1999). Experimental studies with Strongyloides papillosus in goats. Onderstepoort Joumal of Veterinary Research, 66, 191-235.

Romeis, B. V. (1954). Mykroskopycheskaia tekhnyka [Microscopic techniques]. Foreign Literature Publishing, Moscow (in Russian).

Taira, N. (1992). Sudden death of calves by experimental infection with Strongyloides papillosus. I. Parasitological observations. Veterinary Parasitology, 42, 247-256.

Tsuji, N., Itabisashi, T., Nakamura, Y., Taira, N., Kubo, M., Ura, S., \& Genno, A. (1992). Sudden cardiac death in calves with experimental heavy infection of Strongyloides papillosus. Journal of Veterinary Medical Science, 54, 1137-1143.

Turner, J. (1959). Experimental strongyloidiasis in sheep and goats. II. Multiple infections: Development of acquired resistance. Joumal of Parasitology, 45(1), 76-86.

Ura, S. (1993). Sudden death of calves by experimental infection with Strongyloides papillosus. IV. Electrocardiographic and pneumographic observations at critical moments of the disease. Veterinary Parasitology, 47, 343-347.

Ura, S., Nakamura, Y., Tsuji, N., \& Taira, N. (1992). Sudden death of calves by experimental infection with Strongyloides papillosus. II. Clinical observations and analysis of critical moments of the disease recorded on videotape. Veterinary Parasitology, 44, 107-110. 